\title{
Preparation and Characterization of Chitosan-Insulin-Tripolyphosphate Membrane for Controlled Drug Release: Effect of Cross Linking Agent
}

\author{
Holanda Adriana Lima1, Fook Marcus Vinícius Lia², Swarnakar Ramdayal ${ }^{3 *}$ \\ ${ }^{1}$ Department of Physiotherapy, Centre for Higher Education and Development, Faculty of Medical Sciences \\ of Campina Grande, Campina Grande, Brazil \\ ${ }^{2}$ Department of Materials Engineering, Center of Sciences and Technology, Federal University of Campina \\ Grande, Campina Grande, Brazil \\ ${ }^{3}$ Department of Chemical Engineering, Center of Sciences and Technology, Federal University of Campina \\ Grande, Campina Grande, Brazil

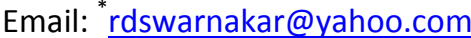

Received 1 August 2014; revised 29 August 2014; accepted 10 September 2014

Copyright (C) 2014 by authors and Scientific Research Publishing Inc.

This work is licensed under the Creative Commons Attribution International License (CC BY). http://creativecommons.org/licenses/by/4.0/

(c) (;) Open Access

\section{Abstract}

The term Diabetes Mellitus (DM) comprises a group of metabolic disorders characterized by chronic hyperglycemia resulting from defects in the secretion and/or action of insulin. The Insulin therapy constitutes the preferred treatment for DM, consisting of daily subcutaneous insulin injections to control blood glucose levels. The chitosan studied for Biomedicine is a biomaterial that can be used for controlled release of drugs whose release rate can be controlled by Sodium Tripolyphosphate (TPP), which is an ionic cross linker of the chitosan. Present study, therefore, was aimed to develop and evaluate membranes of chitosan and chitosan cross linked by TPP for use in controlled release of insulin system, with the purpose of obtaining an alternative to the injectable administration of this drug. The developed membranes were characterized by the techniques of Fourier Transform Infrared spectroscopy (FTIR), Scanning Electron Microscopy (SEM), Energy Dispersive X-ray Spectroscopy (EDX), High Performance Liquid Chromatography (HPLC) and Evaluation of Cell Viability of Macrophages (MTT). With the FTIR technique the interaction between chitosan, tripolyphosphate and insulin was identified. Chemical elements present in chitosan, insulin and sodium tripolyphosphate membranes were detected by EDX technique. By SEM technique, the changes in the morphology of the membrane containing insulin, with the presence of granular particles of varying sizes, could be observed when compared to pure chitosan. With HPLC assay insulin was identified and it was shown that it gets separated from chitosan membrane even when the membrane was cross linked by the TPP, though at a reduced rate. The cros"Corresponding author.

How to cite this paper: Lima, H.A., Lia, F.M.V. and Ramdayal, S. (2014) Preparation and Characterization of ChitosanInsulin-Tripolyphosphate Membrane for Controlled Drug Release: Effect of Cross Linking Agent. Journal of Biomaterials and Nanobiotechnology, 5, 211-219. http://dx.doi.org/10.4236/jbnb.2014.54025 
slinking agent was effective to control the rate of insulin release. The biocompatibility of the prepared membranes was confirmed by cell viability of macrophages using the MTT assay. The developed membranes, therefore, have potential for use as a biomaterial in controlled release systems for insulin.

\section{Keywords}

\section{Biomaterials, Diabetes Mellitus, Insulin-Chitosan-TPP Membranes, Controlled Release of Drugs}

\section{Introduction}

Diabetes mellitus, a metabolic disease characterized by an abnormal increase of blood glucose and resulting from defects in secretion and/or action of insulin by the pancreas, is considered as a global epidemic. It represents a major challenge for health systems around the world. According to the World Health Organization (WHO), the worldwide number of people with this disease was 177 million in 2000 and expected to reach 350 million people by 2025 [1].

Most treatments for diabetes are insulin-based and involve the daily administration of multiple subcutaneous injections, which promote discomfort to the patient, especially children [2]. Thus, the aim of the present work is to find a less traumatic alternative to insulin administration. Accordingly, the development of a delivery system which can perform this function is needed. Due to their various applications and features, especially in controlled drug release therapies, the polymers are among the most widely used excipients. Modifying the properties of a polymer, in which the active ingredient is dispersed or dissolved, a matrix system for sustained or controlled drug release may be prepared [3].

Among the biopolymers chitosan, being abundant and non-toxic, stands out and has been used for various purposes. It is indicated for metal ions complexing agent and as a basic element for making controlled drug release matrixes. Recently, thin chitosan membranes have already been subjected to such evaluations, especially due to its physicochemical characteristics, such as easy formation of gels, filmogenic capacity and good mechanical properties [4]. Chemical modifications of chitosan by means of crosslinking reactions can produce materials with a wide range of physical, mechanical and biological properties. Sodium tripolyphosphate (TPP), which contains an anion of low molecular weight, has been used in the ionic crosslinking process of chitosan with the aim of optimizing the use of this polymer for controlled release drug delivery system application [5].

In this research chitosan, pure and TPP crosslinked, in which insulin was dispersed to form a composite membrane, has been used as a polymer matrix. Thereby, the desired controlled release of insulin is expected. The developed membranes were characterized by the techniques of Fourier Transform Infrared spectroscopy (FTIR), Scanning Electron Microscopy (SEM), Energy Dispersive X-ray Spectroscopy (EDX), High Performance Liquid Chromatography (HPLC) and Evaluation of Cell Viability of Macrophages (MTT).

The prepared membrane's possible use in controlled drug delivery systems via a transdermal and/or oral route for the treatment of individuals with Diabetes Mellitus is suggested.

\section{Materials and Methods}

\subsection{Materials}

Chitosan $\left(\mathbf{C}_{\mathbf{1 2}} \mathbf{H}_{\mathbf{2 4}} \mathbf{N}_{\mathbf{2}} \mathbf{O}_{\mathbf{9}}\right)$-Chitosan, $75 \%$ - 85\% deacetylated, molecular weight (190,000 - 310,000 daltons), degree of polymerization from 1186 to 1924, provided by Sigma Aldrich ${ }^{\circledR}$. Batch 3804 MKBC. Glacial acetic acid $\left(\mathbf{C}_{2} \mathbf{H}_{4} \mathbf{O}_{2}\right)$ - Vetec ${ }^{\circledR}$ Química Fina Ltda, with analytical grade. Batch 0801000 . Sodium Hydroxide $(\mathbf{N a O H})$ Vetec ${ }^{\circledR}$ Vetec ${ }^{\circledR}$ Química Fina Ltda, with analytical grade, molar mass 39.9971 g/mol. Batch 08071098. Insulin $\left(\mathrm{C}_{257} \mathrm{H}_{383} \mathrm{~N}_{65} \mathrm{O}_{77} \mathrm{~S}_{6}\right)$-Commercial Human Insulin liquid-Novolin $\mathrm{N}$, manufactured by the laboratory Nordisk Novo Pharmaceuticals of Brazil Ltda, Batch AS6 1049 provided by public health units of the region and commercial Human Insulin powder (I2643) provided by Sigma Aldrich ${ }^{\circledR}$, molar mass (5807.57 g/mol). Batch 096K03811V. It is worth mentioning that only the liquid insulin was used for making membranes. Powder insulin only was used, in this research, to perform the characterization by Scanning Electron Microscopy (SEM) and 
High Performance Liquid Chromatography (HPLC). Sodium tripolyphosphate $\left(\mathrm{Na}_{5} \mathbf{O}_{10} \mathbf{P}_{3}\right.$ )—Sigma-Aldrich ${ }^{\circledR}$, molar mass (367.86). Batch 16529COV. Lysozyme-Sigma Aldrich ${ }^{\circledR}$. Phosphate Buffered Saline (PBS)-Sigma Aldrich ${ }^{\circledR}, \mathrm{pH}=7.4$. Batch 049K8204. Sodium sulfate $\left(\mathbf{N a}_{2} \mathbf{S O}_{4}\right)$-Carlos Erba Brazil, molar mass (142.04). Acetonitrile $\left(\mathbf{C H}_{3} \mathbf{C N}\right)$-Vetec ${ }^{\circledR}$ Fine Chemicals Ltd., molar mass (41.05). Batch 1008941.

\subsection{Animals}

For cytotoxicity assay the source of peritoneal macrophages used was male mice of Swiss type, provided by the vivarium of the Faculty of Pharmaceutical Sciences of Araraquara, UNESP. All procedures that used animals were conducted according to the norms of the Brazilian Society of Laboratory Animal Science (SBCAL) and as advised by the local Ethics Committee.

\subsection{Preparation of Chitosan Membranes}

The chitosan membranes were prepared by solvent evaporation method [6] by dissolving the polymer in a solution of acetic acid $(1 \% \mathrm{v} / \mathrm{v})$, under magnetic stirring for a period of 24 hours, to a final concentration of the polymer solution being $1 \% \mathrm{w} / \mathrm{v}$. Then, to remove Insoluble substances, a vacuum filtration was performed. After filtration, the solution was kept under magnetic stirring, where, for complete neutralization of the acid, 1M sodium hydroxide was added dropwise and the $\mathrm{pH}$ of the solution was constantly measured until neutrality was reached $(\mathrm{pH}=7)$.

The solution thus formed was distributed in Petri dishes of $5.5 \mathrm{~cm}$. The final volume of the solution in each dish was $5 \mathrm{ml}$ which was dried in a refrigerator at $8^{\circ} \mathrm{C}$ for 5 days till the solvent got evaporated completely. After drying, the Petri dishes with the membranes were capped and kept refrigerated.

\subsection{Incorporation of Insulin in Chitosan Membrane}

The incorporation of insulin was carried out using the same technique, of solvent evaporation in the Petri dishes, as described for preparation of chitosan membranes (Section 2.3). However, after neutralizion, the chitosan solution was distributed in Petri dishes and insulin was added to each dish, such that in the end each $5 \mathrm{ml}$ of chitosan contained $1 \mathrm{ml}(100 \mathrm{IU})$ of insulin. Insulin was slowly mixed with chitosan with the aid of a glass rod. The dishes were then placed in the refrigerator at $8^{\circ} \mathrm{C}$ for drying.

\subsection{Incorporation of Sodium Tripolyphosphate (TPP) in Chitosan Membrane}

The incorporation of TPP was carried out using the same technique, of solvent evaporation in the Petri dishes, described for obtaining chitosan membrane (Section 2.3). However, after neutralization of the chitosan solution tripolyphosphate $(0.1 \% \mathrm{w} / \mathrm{v})$ was added to have a final concentration of $1 \%$ polymer solution $(\mathrm{v} / \mathrm{v})$ under magnetic stirring for a period of 15 minutes [7]. Then, the solution was poured into Petri dishes. The remaining steps were followed in the same order as described for the preparation of chitosan membranes and incorporation of insulin (Section 2.4).

The membranes thus prepared were designated as: Q (Control group-pure chitosan membrane), QI (Experimental group 1-chitosan membrane with insulin) and QIT (Experimental Group 2-chitosan, tripolyphosphate and insulin membrane) and subsequently characterized.

\subsection{Characterization Techniques}

To identify the chemical compounds present in the prepared membranes, a Perkin Elmer Spectrum 400 FTIR/ FTNIR Spectrometer with scanning from 4000 to $400 \mathrm{~cm}^{-1}$, a resolution of $4 \mathrm{~cm}^{-1}$ and 20 scans was used. Scanning Electron Microscopy (SEM), HITACHI ${ }^{\circledR}$, Model TM 1000, coupled with systems for chemical microanalysis by Energy Dispersive Spectroscopy-EDX, was performed to obtain morphological information on the membrane surface. Chromatographic analysis was based on the method of High Performance Liquid Chromatography (HPLC) using an Ultra-Fast LC System (UFLC) from Shimadzu equipped with two pumps (LC 20AD), with DGU 20A3, which offers degas options. Furthermore, the apparatus has: column oven (CTO 20A), UV visible detector with deuterium lamp (SPD 20A), a system controller interface (20A MBC) and monitoring by LC-Solution Software. Membranes containing chitosan, chitosan/insulin and chitosan/insulin/tripolyphosphate 
were used for this test. The membranes were individually cut and each one was placed in a beaker containing 40 $\mathrm{mL}$ of sodium sulfate buffer solution with $\mathrm{pH}=2.4$ and stirred in a magnetic stirrer $(100 \mathrm{rpm})$ for 60 minutes. After stirring the supernatant liquid was chromatographed by Ultra-Fast LC (UFLC) System from Shimadzu. For the preparation of the standard solution powdered human insulin (Sigma Aldrich) diluted in the mobile phase described below, concentration of $2 \mathrm{mg} / \mathrm{mL}$, was used. The chromatographic separation was performed with the aid of a C18 $50 \times 3.0 \mathrm{~mm}$ ID Shimadzu Shim-Pac analytical column, which was maintained at $40^{\circ} \mathrm{C}$. A binary method where the mobile phase consisted of a mixture of acetonitrile and buffer solution of $0.2 \mathrm{M}$ sodium sulfate (30:70 v/v) was used. The $\mathrm{pH}$ was adjusted to 2.4 with $\mathrm{H}_{2} \mathrm{SO}_{4}$ [8] [9]. The eluent flow rate was of $1.0 \mathrm{ml} \mathrm{min}{ }^{-1}$. The volume of sample injected was $20 \mu \mathrm{L}$. Detection was at a wavelength of $214 \mathrm{~nm}$, with the total elution time of 5 minutes.

In order to follow ISO 10993-5 norm, which recommends in vitro cytotoxicity as initial tests to evaluate the biocompatibility of any material for use in biomedical devices, we chose the test MTT, [3-(4.5-dimethylthiazol2yl)]-2.5 diphenyl tetrazolium bromide, for assessing the cell viability of macrophages. To realize this step, it was necessary to obtain peritoneal exudate cells using 6 Swiss mice previously stimulated by intraperitoneal injection of $3.0 \mathrm{~mL}$ of sodium thioglycolate (Difco Lab LTD) of 3.0\%, three days before the collection of cells. After this period, the animals were euthanized in $\mathrm{CO}_{2}$ inhalation chamber. Peritoneal exudate macrophages were collected for preparation of the cell suspension. The number of cells was determined by counting in a Neubauer chamber (Hemocytometer) in a 1:100 dilution of the Lazarus liquid. The cells were adjusted to a concentration of $5 \times 10^{6}$ Cells in RPMI-1640-C media. $100 \mu \mathrm{L}$ of the suspensions of peritoneal exudate cells of mice per well was distributed in a 96 well flat bottom sterile plate (Corning, Inc.). A membrane disc made from chitosan, chitosan/insulin and chitosan/insulin/TPP was then added. 3 discs from each composition of membrane were used for each animal. In other wells of the plate with the same conditions, $100 \mu \mathrm{L}$ of LPS (bacterial lipopolysaccharide derived from E. coli, purchased from Sigma Aldrich at a concentration of $10 \mu \mathrm{L}$, or only culture medium (negative control) were added. The plates were incubated for $24 \mathrm{~h}$ at $37^{\circ} \mathrm{C}$ in an oven containing $5 \% \mathrm{CO}_{2}$ (Forma Scientific, USA). After this period, $100 \mu \mathrm{L}$ of a solution of MTT (Across Organics), $0.5 \mathrm{mg} / \mathrm{ml}$ in RPMI1640 medium was added to cell culture. The plate was then incubated for 3 hours in the same conditions. After this incubation, the supernatants were discarded and adherent cells treated with $100 \mu \mathrm{L}$ of isopropanol (Mallinckrodt) to solubilize the formed crystals of formazan. The reading of the optical density was determined using a spectrophotometer (Multiskan Ascent, Labsystems Research Tech. Div, Helsinki, Finland) in UV/visible at $540 \mathrm{~nm}$ with reference filter of $620 \mathrm{~nm}$ [10]. The Cell viability was calculated as a percentage, considering the negative control as $100 \%$ viability.

\section{Results and Discussion}

\subsection{Fourier Transform Infrared Spectroscopy (FTIR)}

Figure 1 shows the infrared spectrum of chitosan (Q), insulin-chitosan (QI) and insulin-chitosan-tripolyphosphate (QIT) membranes.

Comparing the spectra of Q and QI, in the spectrum of chitosan with insulin, in addition to the increase in the intensity of absorbance, a slight displacement of the characteristic amide I $\left(1646 \mathrm{~cm}^{-1}\right)$ and amide II $\left(1555 \mathrm{~cm}^{-1}\right)$ bands was noticed. These modifications of the spectrum may suggest a possible interaction between chitosan and insulin.

While studying the interaction between chitosan and some drugs it was found that, in the FTIR spectra of chitosan-insulin microparticles, the chitosan bands overlapped with those of insulin resulting in an increase in the intensity of the carbonyl $\left(1654 \mathrm{~cm}^{-1}\right)$ and amine $\left(1540 \mathrm{~cm}^{-1}\right)$ bands. This behavior was attributed to the interaction between chitosan and insulin [7].

In the spectrum of the membrane containing insulin (QI), when compared to the chitosan membrane without insulin (Q), a change in the intensity of the absorbance band at around $3331 \mathrm{~cm}^{-1}$, was observed. This event may be related to the fact that in this range of absorbance the insulin contains the same functional groups, thus causing increase in the intensity of this band due to the increased concentration of $\mathrm{OH}$ groups. Likewise, it should be noted that, under conditions of this experiment, the vibration mode of the hydroxyl functional group was not inhibited.

In insulin-chitosan-tripolyphosphate (QIT) spectrum (Figure 1), an increase in absorbance between 3000 - 


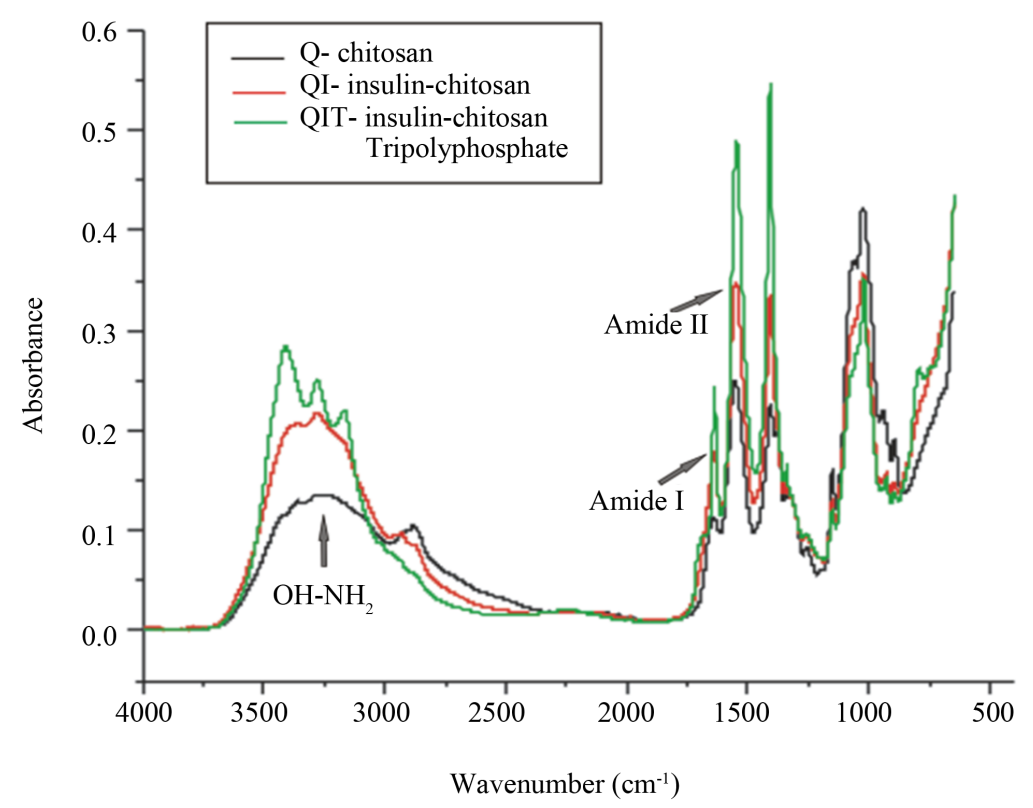

Figure 1. FTIR spectra of Q, QI and QIT membranes.

$3500 \mathrm{~cm}^{-1}$ with profile changing in the region $3412 \mathrm{~cm}^{-1}$ is observed. Certainly these results may be associated to the ionic cross linking effect of the cross linking agent used which resulted in the vibration mode change of the $\mathrm{OH}$ group and indicated a specific vibration of the $\mathrm{NH}_{2}$ group.

An increase in the band intensitis at 1639, 1547 and $1409 \mathrm{~cm}^{-1}$, possibly due to the interaction between chitosan, tripolyphosphate and insulin, was also observed. Wu et al. (2005) [11], analyzing chitosan-tripolyphosphate nanoparticles, found similar results and concluded that the tripolyphosphate groups of TPP linked with ammonium groups in chitosan. A band at $794 \mathrm{~cm}^{-1}$ characteristic of TPP was also noticed. The absence of a band in the region around $1220 \mathrm{~cm}^{-1}$ (P = O TPP), reported by Gierszewska-Drużyńska, Ostrowska-Czubenko (2010) and Pieróg et al. (2009), is obseved. This could be due to the low concentration of TPP used in the present study [12] [13].

\subsection{Scanning Electron Microscopy (SEM) and Energy Dispersive X-Ray Spectroscopy (EDX)}

By analyzing SEM image for the morphology of pure chitosan membrane (Figure 2(a)), a uniform, smooth, flat and no presence of visible pores surface was observed. Thus, it is characterized as a dense membrane. During the studies on the morphology of chitosan film [14] [15] also found it to have a flat and dense surface. By introducing insulin in chitosan membrane (Figure 2(b)), the presence of granular particles of varying sizes can be noticed. This may be attributed to a chemical activity sufficient to the formation of agglomerates whose morphology differed from the structure of the polymer alone. This phenomenon may be associated to a kind of encapsulation. The micrograph of chitosan membrane with both sodium tripolyphosphate (TPP) and insulin is shown in Figure 2(c). A rod-shaped morphology of different sizes which is spread throughout the membrane surface can be verified.

In Figure 3(a), in the EDX spectrum, the elements O, C, N present in the chitosan membrane itself are shown. In addition the element $\mathrm{Na}$, probably remnant of the neutralization process, is seen. The chemical analysis of Chitosan Membrane QI, obtained by EDX (Figure 3(b)), showed a change in its chemical composition. Herein, the observed presence of element sulfur thus confirmed the presence of insulin in the film. Certainly this change in morphology, when compared with the micrographs shown in Figure 2(a) and Figure 2(b), can be attributed to the phenomenon of cross-linking occurring primarily between the chains of chitosan and TPP. Therefore, the association of the element of crosslinker and of insulin altered the morphology of the chitosan membrane. In the analysis by EDX (Figure 3(c)) the presence of phosphorus (P) and sulfur (S) is distinguished. 

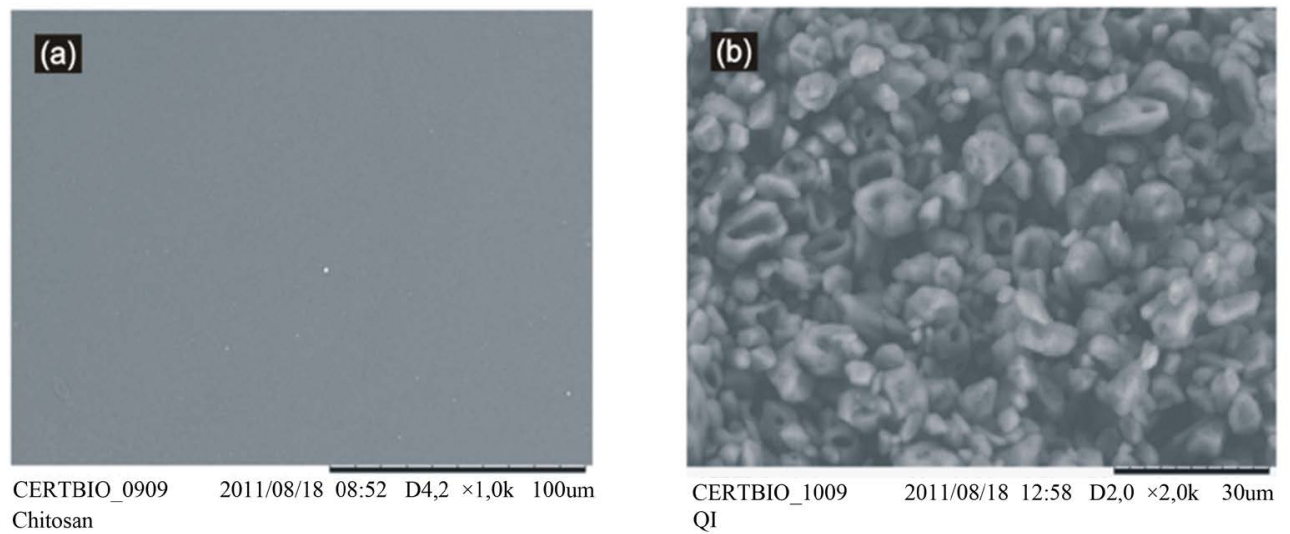

Chitosan

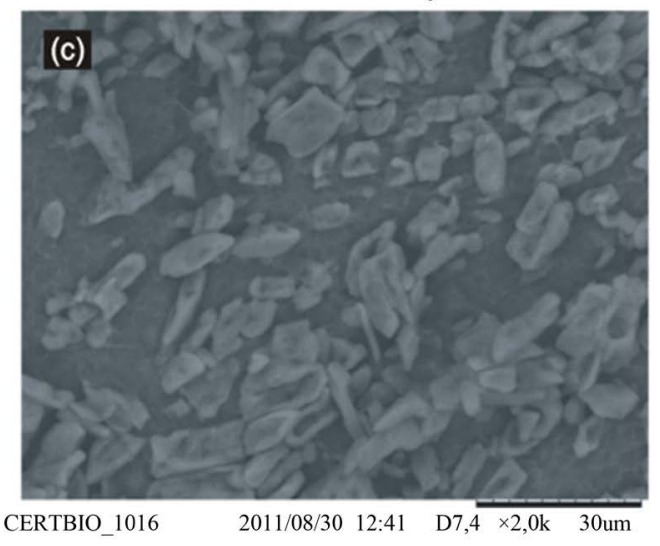

QIT

Figure 2. SEM images of the surfaces of (a) Chitosan Membrane Q, 1000×; (b) Membrane QI, 2000×; and (c) Membrane QIT, 2000×.
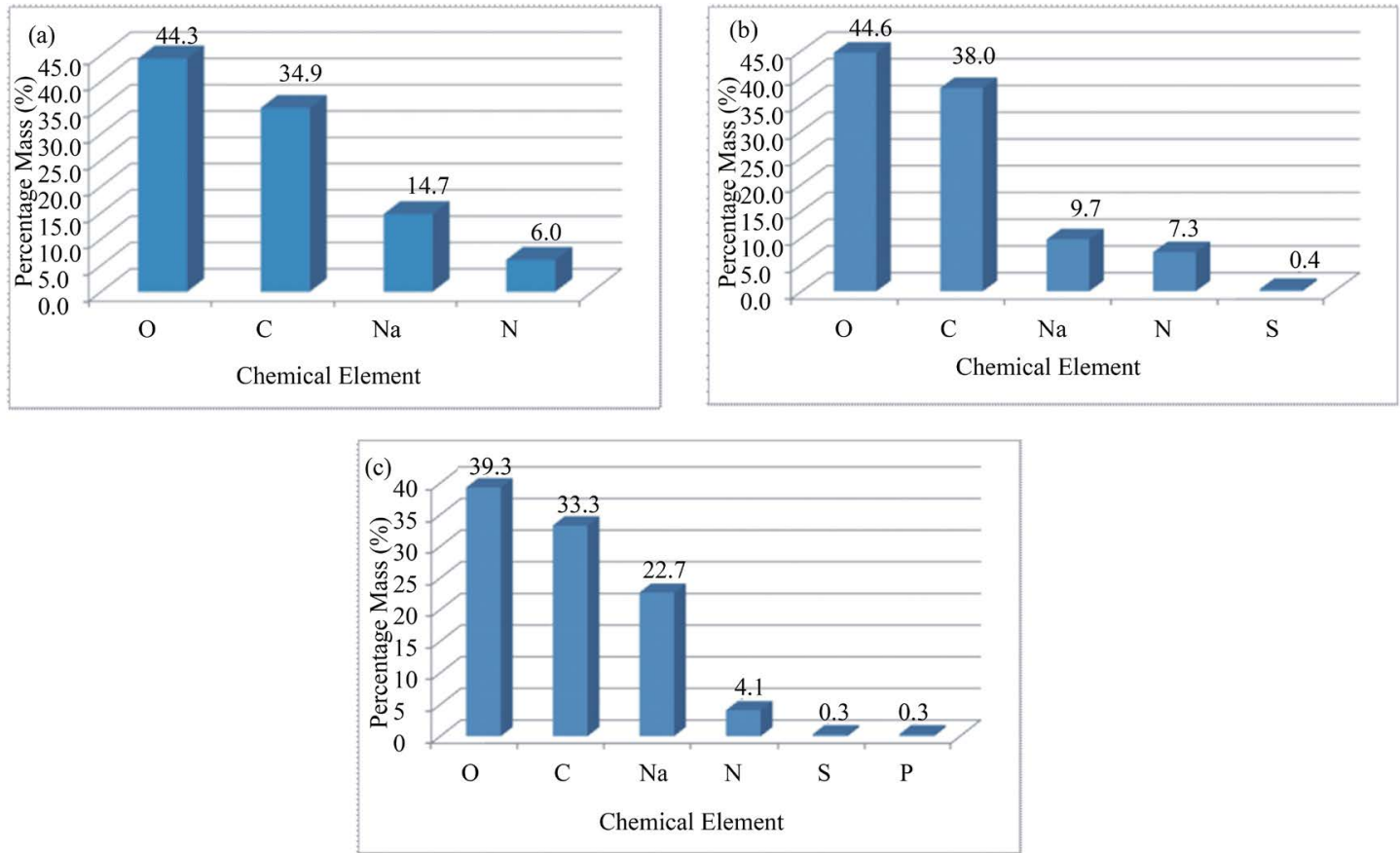

Figure 3. EDX, chemical element percent mass of (a) chitosan membrane Q; (b) chitosan membrane QI; and (c) chitosan membrane QIT. 


\subsection{High Performance Liquid Chromatography (HPLC)}

The high performance liquid chromatography (HPLC) can be used to identify compounds by comparing the sample retention time to a standard reference [16] [17].

In Figure 4 the chromatograms of the supernatant samples of chitosan, chitosan-insulin and chitosan-insulintripolyphosphate membranes are presented.

In the range of 0.5 and 0.8 minutes a overlapping of chitosan characteristic peaks can be observed. It can also be noticed that insulin, separated from the other two membranes: QI and QIT, shown as black and pink peaks respectively, had a retention time of approximately one minute. This time is identical to that of standard insulin. It, therefore, suggests that insulin has been identified and it gets separated from the chitosan membrane without undergoing any structural change. It is noteworthy that the area of the insulin peak of QIT is relatively smaller. Thus, insulin is released with difficulty from the chitosan membrane when crosslinked by TPP.

\subsection{Evaluation of Cell Viability of Macrophages}

The objective of this test was to determine the cell viability on the surface of the produced membranes for their use in living organisms. Figure 5 illustrates the results of this test.

Cells in culture medium (RPMI-16,400) were used as a control, being equivalent to $100 \%$ viability and are

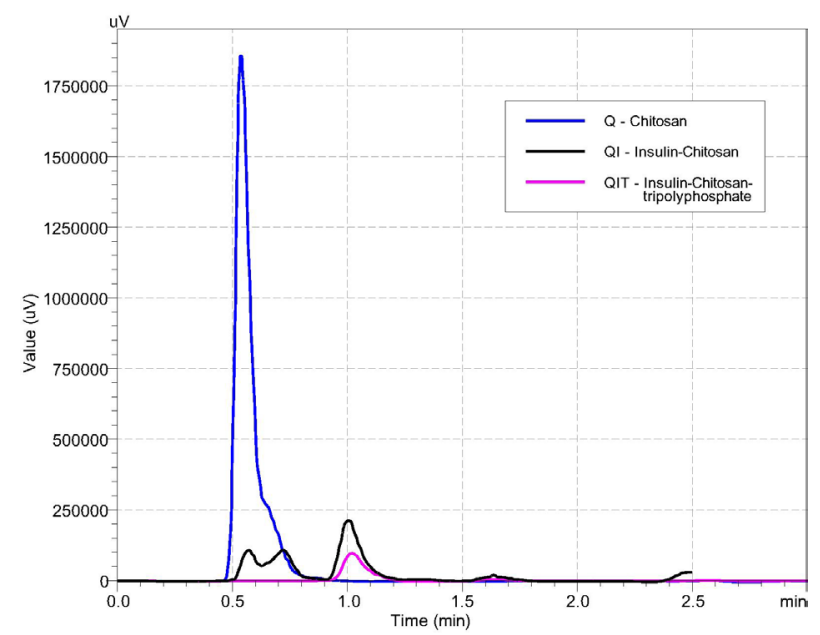

Figure 4. Chromatograms of chitosan, Q; chitosan-insulin, QI and chitosan-insulin-TPP, QIT membranes.

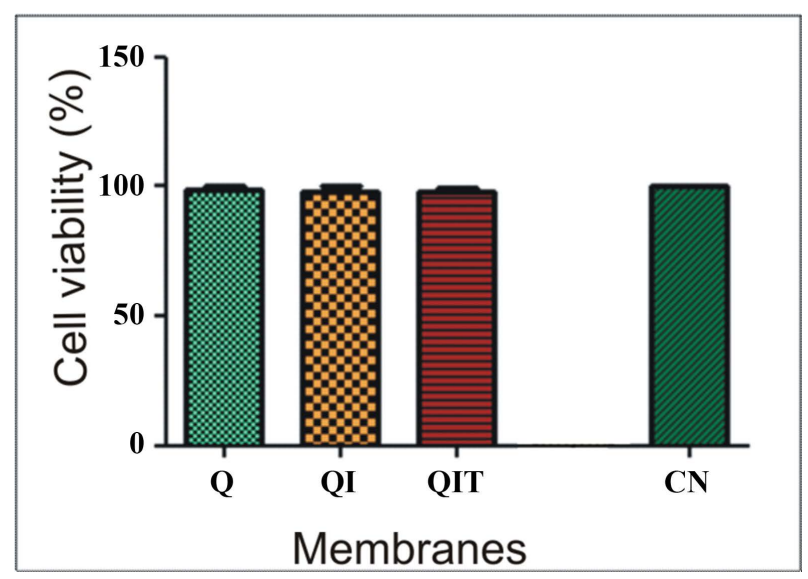

Figure 5. Viability of Swiss mouse macrophages in the presence of membranes. Q, Chitosan; QI, Chitosan-Insulin; QIT, Chitosan-insulin-TPP; and CN, negative control. 
shown in the last column $(\mathrm{NC}=$ negative control $)$ of Figure 5 . The results shown in Figure 5 were obtained using the mean ( \pm Standard Deviation) value of peritoneal exudate cells of 6 animals and 3 membranes of each composition per animal.

Comparing to a minimum of 50\% biocompatibility required for cytotoxicity test [18], the results in Figure 5 for the membranes Q, QI, and QIT, shown in first, second and third columns respectively, analyzed in this assay, demonstrate viability for their use as biomaterials since all the samples exhibited similar behaviors being equivalent to that of the negative control, $\mathrm{CN}$, and the values obtained were above $90 \%$.

The in vitro cytotoxicity assay is considered to be the first test to evaluate the biocompatibility of the materials to be used in health and after being proven as non-toxic, continuity can be given to carrying out other necessary tests on laboratory animals [19]. Thus, from the results obtained in this study, it can be inferred that all the produced membranes may be tested in vivo assays.

\section{Conclusions}

The technique of spectroscopy in the infrared region identified, for the prepared membranes, the interaction between chitosan, insulin and tripolyphosphate through changes in absorption regions $3000-3500 \mathrm{~cm}^{-1}$ and 1600 $1700 \mathrm{~cm}^{-1}$, attributed to hydroxyl and amino groups, respectively. Besides, the appearance of a band at $794 \mathrm{~cm}^{-1}$ characteristic of tripolyphosphate has been observed.

The Energy Dispersive X-ray Spectroscopy (EDX) technique verified the presence of chemical elements present in chitosan, insulin and sodium tripolyphosphate in the membranes.

With the technique of scanning electron microscopy, it was possible to notice a change in the morphology of the membrane due to the presence of granular particles of varying sizes. The presence of these particles and the chemical element sulfur (observed in EDX) is indicative of the presence of insulin in the membranes developed.

The liquid chromatography (HPLC) test identified insulin separation from chitosan membrane and even when the membrane was crosslinked by the TPP, though released relatively with difficulty.

The biocompatibility of the membranes was confirmed with tests for assessing cell viability of macrophages.

Considering the above, it can be concluded that the process described in the methodology for obtaining membranes Q, QI, and QIT proved effective.

The results of these observed modifications suggest the presence of insulin incorporated in chitosan membrane with or without tripolyphosphate. This crosslinking agent was effective to control the rate of insulin release from the chitosan membrane

We suggest a possible use of this membrane in controlled drug delivery systems, through a transdermal and/or buccal route. This way it shall be a comfortable, effective and safe, being less invasive, painless and more prolonged action method.

\section{Acknowledgements}

The authors are grateful to the Brazilian Agency CNPq (Conselho Nacional de Desenvolvimento Científico e Tecnológico) for the financial support. We are also grateful to the authors of the references cited in this paper that helped in the improvement of quality.

\section{References}

[1] WHO (2008) The Global Burden of Disease (2004 Update). http://www.who.int/healthinfo/global_burden_disease/GBD_report_2004update_full.pdf

[2] Khafagy, E.-S., Morishita, M., Onuki, Y. and Takayama, K. (2007) Current Challenges in Non-Invasive Insulin Delivery Systems: A Comparative Review. Advanced Drug Delivery Reviews, 59, 1521-1546. http://dx.doi.org/10.1016/j.addr.2007.08.019

[3] Rios, M. (2005) Polymers for Controlled Release: Formulation Follows Function. Pharmaceutical Technology, 29, 4250 .

[4] Vilar, G., Tulla-Puche, J. and Alberício, F. (2012) Polymers and Drug Delivery Systems. Current Drug Delivery, 9, 1-27. http://dx.doi.org/10.2174/156720112801323053

[5] Calvo, P., Remuñàn-Lopez, C., Vila-Jato, J.L. and Alonso, M.J. (1997) Chitosan and Chitosan/Ethylene Oxide-Propylene Oxide Block Copolymer Nanoparticles as Novel Carriers for Proteins and Vaccines. Pharmaceutical Research 14, 1431-1436. http://dx.doi.org/10.1023/A:1012128907225 
[6] Osorio, S.M.L. (2007) Novel Polymeric Systems Based on Natural Materials: Development and Biological Performance. Master Dissertation, Escola de Engenharia, Universidade do Minho, Braga.

[7] Boonsongrit, Y., Mueller, B.W. and Mitrejev, A. (2008) Characterization of Drug-Chitosan Interaction by 1H NMR, FTIR and Isothermal Titration Calorimetry. European Journal of Pharmaceutics and Biopharmaceutics, 69, 388-395. http://dx.doi.org/10.1016/j.ejpb.2007.11.008

[8] Xu, X., Fu, Y., X., Hu, H., Duan, Y. and Zhang, Z. (2006) Quantitative Determination of Insulin Entrapment Efficiency in Triblock Copolymeric Nanoparticles by High-Performance Liquid Chromatography. Journal of Pharmaceutical and Biomedical Analysis, 41, 266-273. http://dx.doi.org/10.1016/j.jpba.2005.10.016

[9] Yilmaz, B. and Kadioglu, Y. (2010) Development and Validation of HPLC Method for Determination of Human Insulin in Pharmaceutical Preparation. International Journal of Pharmaceutical Sciences Review and Research, 2, 40.

[10] Mosmann, T. (1983) Rapid Colorimetric Assay for Cellular and Survival: Application to Proliferation and Citotoxicity Assays. Journal of Immunological Methods, 65, 55-63. http://dx.doi.org/10.1016/0022-1759(83)90303-4

[11] Wu, Y., Yang, W., Wang, C., Hu, J. and Fu, S. (2005) Chitosan Nanoparticles as a Novel Delivery System for Ammonium Glycyrrhizinate. Pharmaceutical Nanotechnology, 295, 235-245.

[12] Gierszewska-Druzznska, M. and Ostrowska-Czubenko, J. (2010) The Effect of Ionic Crosslinking on Thermal Properties of Hidrogel Chitosan Membranes. Progress on Chemistry and Application of Chitin and Its Derivatives, 15, $25-32$.

[13] Pieróg, M., Gierszewska-Druzznska, M. and Ostrowska-Czubenko, J. (2009) Effect of Ionic Crosslinking Agents on Swelling Behavior of Chitosan Hidrogel Membranes. Progress on Chemistry and Application of Chitin and Its Derivatives, 14, 75-82.

[14] Marreco, P.R., Moreira, P.L., Genari, S.C. and Moraes, A.M. (2004) Effect of Different Sterilization Methods on the Morphology. Mechanical Properties and Cytotoxicity of Chitosan Membranes Used as Wound Dressings. Journal of Biomedical Materials Research Part B: Applied Biomaterials, 71, 268-277.

[15] Dallan, P.R.M. (2005) Synthesis and Characterization of Chitosan Membranes for Application in Skin Regeneration. Doctorate Thesis, Universidade Estadual de Campinas, Campinas. (In Portuguese)

[16] Martins, M.T. (2007) Development and Validation of Analytical Methods, Preliminary Study of Stability and Dissolution Test to Determination of the Triazine Antiepileptic Lamotrigine in Tablets. Doctorate Thesis, Universidade Federal do Rio Grande do Sul, Faculdade de Farmácia, Porto Alegre. (In Portuguese)

[17] Watson, D.G. (2012) Pharmaceutical Analysis: A Textbook for Pharmaceutical Chemists. Churchill Livingstone, London.

[18] Bispo, V.M. (2009) Biocompatibility of Nanostructural Chitosan/Poy(Vinyl Alcohol) Blends Chemically Crosslinked with Genipin for Biomedical Applications. Thesis, Federal University of Minas Gerais, Minas Gerais.

[19] Daguano, J.K.M.F., Santos, C. and Rogero, S.D. (2007) Cytotoxicity Analysis of Bioceramics for Use in Systems of Implantations. Revista Matéria, 12, 134-139. (In Portuguese) http://dx.doi.org/10.1590/S1517-70762007000100017 
Scientific Research Publishing (SCIRP) is one of the largest Open Access journal publishers. It is currently publishing more than 200 open access, online, peer-reviewed journals covering a wide range of academic disciplines. SCIRP serves the worldwide academic communities and contributes to the progress and application of science with its publication.

Other selected journals from SCIRP are listed as below. Submit your manuscript to us via either submit@scirp.org or Online Submission Portal.
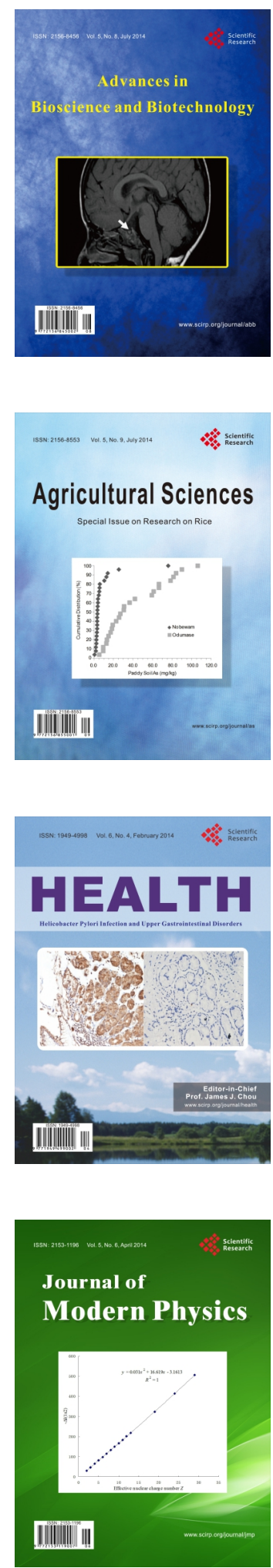
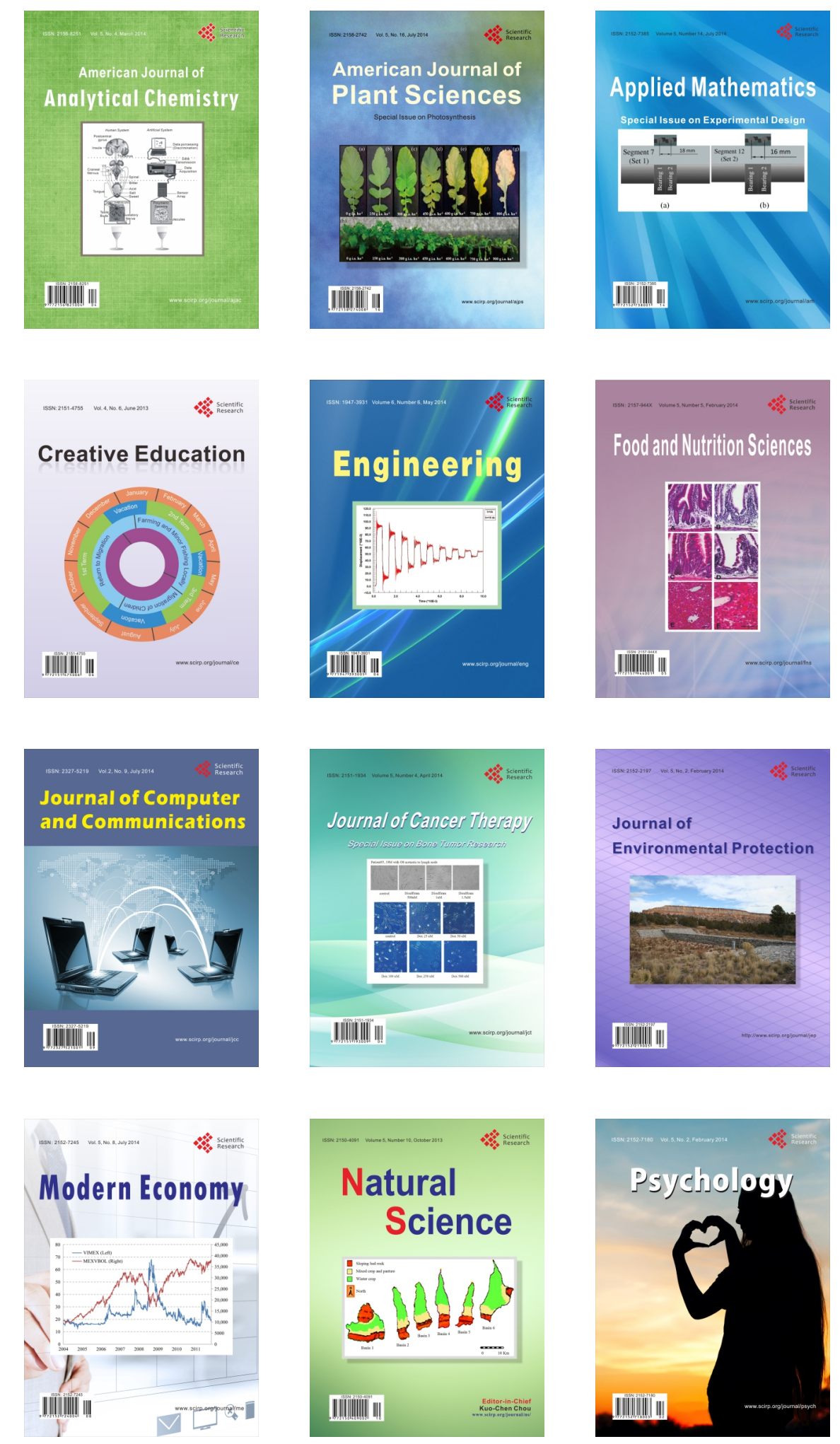